\title{
INTRODUCING THE SISM MODEL- A HOLISTIC APPROACH TO SMME INCUBATION PROGRAMMES
}

\author{
Mwale,B.J., Nyamkure,B. ${ }^{* *}$ Costa, K.***
}

\begin{abstract}
Background: Business incubators provide specialised training and mentorship support to upcoming small to medium businesses. There has been a number of incubation programmes in Gauteng province of South Africa. It has been observed that sometimes, some incubation centres fail to achieve objectives for which they were created and originated. That failure results in losses, particularly for those who had created them and as well as loss of income, time and related resources to the beneficiaries, usually the helpless and needy grassroots SMMEs. As a result, some initiatives through incubation are losing the confidence of those who should benefit or support them, due to the failures related to application and operationalization. In view of the above, this study sought to determine and assess the expected effectiveness and significance of business incubation services on turnover of the Gauteng Province tourism SMMEs sector.
\end{abstract}

Methods: The orientation of this study was hinged upon positivist paradigm with an objective ontological position. By virtue, a random sampling procedure of 103 participants using questionnaires for data collection was used in the study. Moreover, the Cronbach's alpha and Keiser-Meyer-Olkin techniques were used and resulted in the conclusion that the study was structurally valid and reliable. This entailed a critique of the strategies that could optimally support the effective and efficient provision and growth of SMMEs within the tourism sector of the Province. The study achieved that result by using paired-samples t-tests, principal component analysis, frequencies, exploratory factor analysis, and descriptive statistical techniques to evaluate four hypotheses at a $5 \%$ level of significance.

Results: Empirical findings indicated that the respondents (SMMEs Business Owners and Managers) had a certain level of expectation regarding the incubation programme, such as support, training and business linkages. This expectation was mainly directed to the provincial government as he custodian of economic development and growth. Interestingly, the study found out that despite lack of confidence on similar initiatives (SMMEs incubation prgrammes), 
and much reported failures, SMME owners felt there was a need for this type of intervention but caution needs to be exercised in terms of operationalization and sustainability.

Discussion: In this synthesis, current trends, events and practice on a global, regional and local perspectives are closely securitized. Evidence shows that incubators have been successful in encouraging the development of new start-ups by reducing the failure rate of small- and medium-sized companies (Mirza \& Rahmani, 2017). Incubators have become highly popular as a way of cultivating start-ups in both developed and developing countries, whereby they form integral for providing assistance to young businesses in enabling structures (Lalkaka, 2006). Having discovered their value, all those working in the incubation industry continue to seek to discover, describe, calculate, devise, and rate the different aspects of incubation as a sustainable intervention. For that reason, he SISM Model is hereby introduced.

Key Words: Business Incubators, Model, Planning, Strategy, SMMEs 


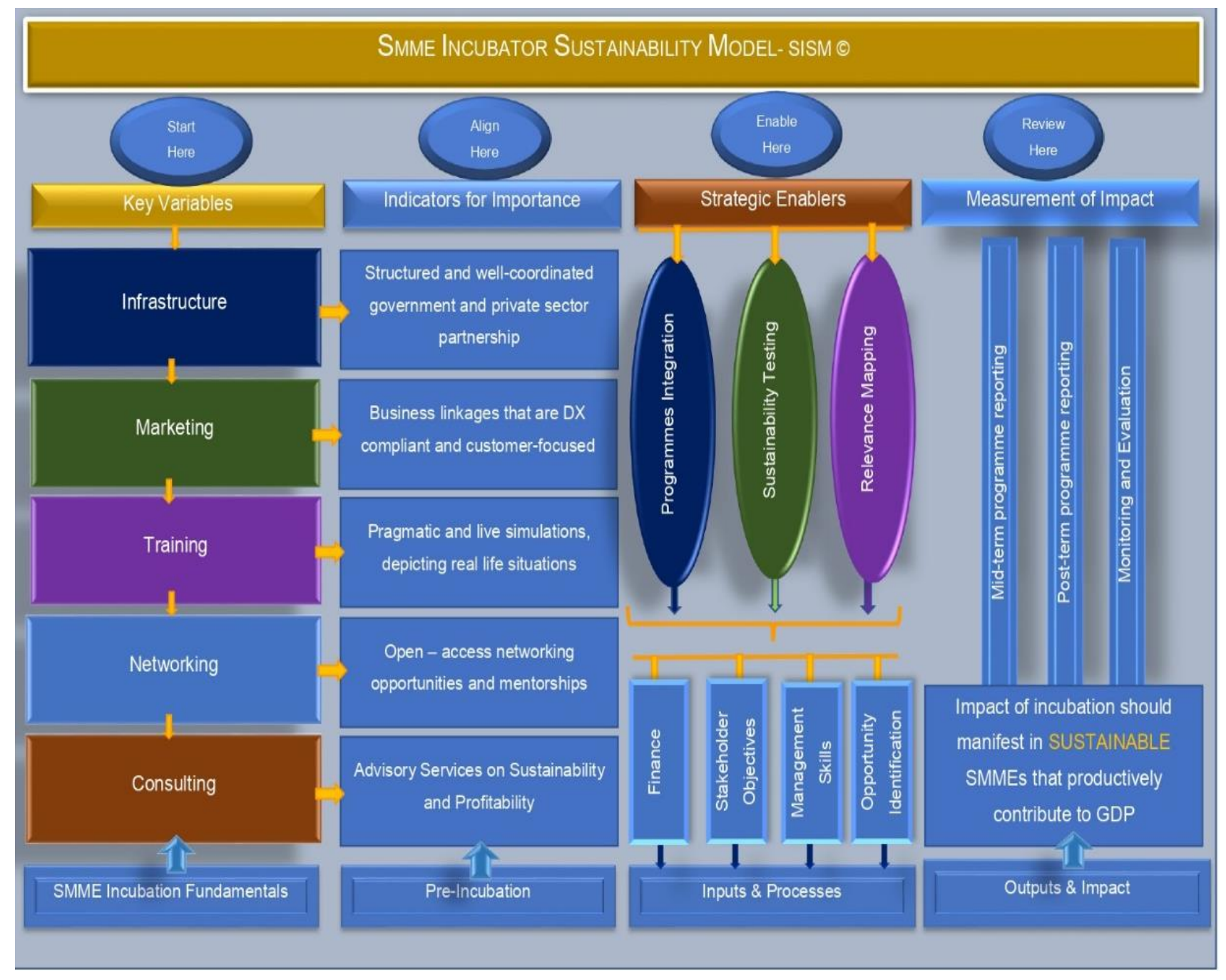

Figure 1: SISM Model for Business Incubation

\section{The SISM Model}

The SISM Model is a proposition that integrates the findings of this study into practical executable step-by-step approach for consideration when embarking on SMME incubation within the tourism sector in particular and other economic sectors in general. It is founded on study recommendations as fundamental input in the business incubator performance and sustainability indicator. Key variable and result areas identified are:

- Infrastructure - It is recommended that the government should register all tourism SMMEs and allocate them with affordable business operating premises. The government can either give them the grants for them to construct the building for the 
premises or they may construct the buildings itself and then allocate offices to the tourism SMMEs. The premises should be installed with effective and latest technology security facilities such as alarms and armed response for the safety of the business owners their employees and of their clients. The government and private sector banks should develop and make available affordable and low cost insurance policies so that in the event of misfortunes befalling the tourism SMMEs, they are safeguarded and indemnified in their operational facilities. All the products made for these tourism SMMEs should be tailor made to meet individual needs of their specific needs.

- Marketing - It is recommended that these tourism SMMEs should be empowered to implement the marketing strategies for their tourism businesses. The empowerment may take the form of funding from the government and private sector funders. During the training period at the incubation, the tourism SMMEs should be given an opportunity to explore all possible avenues for marketing their products. The marketing initiatives that are available to them include: advertising and promotions, marketing networking, demonstrations and exhibitions at local and international fairs and exhibitions. Initiatives for marketing should also be done on their premises. It is therefore, from this backdrop that, the provision of offices and land, mentioned in the section above, should be done on areas which are regularly frequented by tourists and travellers. For instance, domestic exhibition centres can be developed in economic development and business hubs, both of which have high tourists and travellers traffic. These tourism should also be encouraged to form clusters which will help them to network and cross marketing their products and services. From the absence of these services, it is recommended that, the business incubators should only graduate their incubation beneficiaries after they have become competent in all areas, marketing included.

- Training - It is recommended that the training sessions for the owners and runners of tourism SMMEs should be more practical and involving. In the incubation, the tourism SMMEs should be allowed to try, test and trust their ideas in the practical ways. Without practical problem solving of business problems the incubator will be like an academic college and it will lose the essence of its being there. Though the tourism SMMEs should receive training in all business courses, emphasis should be put in certain areas specific for individual business owners. However, the training should be holistic, including: financial literacy, strategic investment, product development, and business networking skills. Season professors and industrial gurus with long industrial 
experience should be recruited to provide training at the incubators. Corporate training type of learning should be discarded for its lack of practicality. University lecture like training also suffers the same weakness as corporate training. Therefore, incubation beneficiaries should be allowed, after training, to go into the field to implement what was taught. The incubators should develop a stringent means of assessing that what they taught was implemented rather than was understood.

Inspite of the above, incubation beneficiaries should be allowed and given an opportunity to interact with tertiary and vocational institutions so that they have access to science laboratories and networking so that they develop new innovative ideas, products and services. Currently, the institutions which have opened their doors for entrepreneurial empowerment training services are University of Johannesburg, University of South Africa, and the University of Wits. In such collaborative initiatives, the incubators and tertiary institutions should have a single training model or curriculum that achieves common goals. Workshops on relevant programmes could be arranged where leading industry captains would come and educate aspiring entrepreneurs.

- Networking - It is recommended that incubation beneficiaries have an open access to networking opportunities with all who include: the incubator managers and employees, incubator advisory board, fellow incubatee companies and employees, local universities and university community members, industry contacts, professional service providers such as lawyers, accountants, marketing specialists, venture capitalists, angel investors, and volunteers. Networking with these stakeholders promotes the gaining of knowledge on where to get which service from. It is during this networking escapades that the potential of the tourism SMMEs is unlock and broaden market opportunities open.

The incubators leadership should have a calendar for a quarterly basis that allows the networking to be held either at the incubation premises or at other exclusive venues. During the event, the leadership may invite the successful tourism entrepreneurs who would act as role models and inspiration for the incubation beneficiaries. Gaining practical insights into real business from the people who have personally gone through experiences has more impact. On the same note, international networking days may also be marked on the calendar so that incubation beneficiaries travel to other countries on exchange programmes when they will spend two to three months on an "attachment" with the foreign mentor. These mentors can be identified in western 
countries such as UK, Sweden and USA. The funding for such trips can be secured from the government, private sector banks and form NGOs which support entrepreneurial development and growth.

Caution, however, should be exercised to ensure that the partners identified for networking and collaboration with make a positive contribution to the development and growth of incubation beneficiaries. Therefore the incubator should do thorough research to identify the candidates for networking with. Tourism SMMEs who thrive on dubious and shoddy deals should not be involved in the networks. To achieve selection and maintenance of strategic networks and business collaborations, benefit and cost matrices should be drawn to allow for the network performance measurement and improvement.

- Consulting Services - Consulting Services - Strategies that could be provided to enhance the effective provision of business incubation services are business collaboration strategies, research and development strategies, marketing and promotion strategies, financial management strategies, networking strategies and project management strategies.

In addition to these key variables discussed above, the inputs to the incubation process require sound measurement, monitoring and evaluation according to critical success factors of the programme during at each stage of existence. Integrating financing models with stakeholder objectives, leadership and management skills and selection process are viewed as pivotal strategic enabler elements. A well articulate and structured combination of variables in the SISM Model are predicators of success for both the incubator and the incubatees. It is from this backdrop that the business incubators should adopt the SMME Incubator Sustainability Model (SISMC) and implement its variables for the effective outcomes and successful tourism SMMEs. 


\section{REFERENCES}

Brown, M. 2002. How to Invest in the New Economy Without becoming an Investment Company. Business Lawyer, pp. 77-83.

Lalkaka, R. 2006. Technology Business Incubators: Critical Determinants of Success. [Online]

Available at:

https://www.researchgate.net/publication/228029738 Technology Business Incubators Crit ical Determinants of Success

[Accessed 02 March 2021].

Mirza, A. \& Rahmani, M. 2017. Role of Incubation Centers in Growth of Small-Scaled Businesses in Afghanistan. SSRN Electronic Journal.

Ryzhonkov, V. 2013. Entrepreneurship, Business Incubation, Business Models \& Strategy Blog. [Online]

Available at: https://worldbusinessincubation.wordpress.com/2013/03/22/426/

[Accessed 30 March 2021].

\section{About Authors}

*Bongani June Mwale is a PhD student at Da Vinci Institute for Technology Management. He may be reached at: mwalebj@icloud.com

**Dr Blondel Nyamkure is an academic and research supervisor at Da Vinci Institute for Technology Management. He may be reached at: blondel@davinci.ac.za

${ }^{* * *} \mathrm{Dr}$ King Costa is a research professor and executive dean at the Global Centre for Academic Research. He may be contacted at: costak@researchglobal.net 